\title{
AUDITORIA DE SERVIÇOS DE ENFERMAGEM
}

Circe de Melo Ribeiro ( $\left.{ }^{*}\right)$

\section{INTRODUÇÃO}

Sempre que alguém usa ou adota um termo novo, que ainda não faz parte da fraseologia própria da classe a qual pertence, começam a surgir dúvidas e críticas a respeito, seja de vocábulo em si, seja de assunto nele contido.

Auditoria é um desses termos; por essa razão procuraremos em primeiro lugar fazer alguns esclarecimentos que justifiquem e/ou expliquem sua inclusão como assunto para tema deste Congresso.

Para ninguém é desconhecido o uso do processo de auditoria, quando se trata de contas de uma empresa, da verificação contábil dos resultados de uma organização ou instituição, ou para a aprovação dos relatórios de governos.

Na linguagem contábil, "auditoria" é entendida como:

1 - exame e verificação formal ou oficial dos livros de contas, cuja finalidade é relatar as condições financeiras ou os resultados das operações de uma empresa, em um período dado, geralmente feito anualmente;

2 - exame e revisão metódica da situação de uma empresa, concluirido com um relatório completo das condições encontradas, sob o ponto-de-vista das suas finanças;

3 - exame judicial de contas para uma corte de justiça, demonstrado em relatório conclusivo, sob o ponto-de-vista contábil;

4 - exame das contas de uma instituição, submetendo-as a comparação com planos pré-estabelecidos, para controle (comprovação) e aprovação. (1)

Certamente, para algumas enfermeiras, é conhecido o uso (adaptação) do processo de auditoria na avaliação do rendimento profissional médico-hospitalar. Isto é feito desde 1918, quando o

$\left(^{\star}\right)$ Docente da Escola de Enfermagem da U.S.P. 
Colégio Americano de Cirurgiões trouxe por bem quantificar a eficiência do Corpo Clínico dos hospitais norte-americanos para fins de avaliação, comparação e credenciamento, através de índices e padrões práticos e objetivos que permitissem evidenciar uma atuação normalizada. A normalização das atividades médicas-hospitalares foi feita após levantamento e estudos comparativos da situação existente naquela época, tomando como padrões os melhores índices encontrados.

Como exemplo podemos citar um dos índices estudados: o coeficiente de mortalidade hospitalar. Nos hospitais considerados de melhor nível assistencial o mínimo encontrado foi de $4 \%$. Este é um dos padrões adotados e aplicados na avaliação do trabalho médico e quando o índice de mortalidade hospitalar (mais de 48 h. de internação) é superior a $4 \%$ sugere ineficiência. Neste caso há recomendação para análise mais profunda da situação a fim de verificar suas causas e decidir sobre as medidas para a devida solução. O objetivo central é a melhoria da assistência, o que poderá ou não envolver medidas primitivas de acordo com os resultados da investigação.

Ao Colégio Americano de Cirurgiões juntaram-se posteriormente o Conselho de Educação Médica, a Associação Médica Americana e mais recentemente a Comissão Conjunta para Credenciamento de Hospitais, reforçando a exigência no que diz respeito a competência e idoneidade do corpo clínico dos hospitais. (2)

Essas organizações atuam nos Estados Unidos somando esforços e são órgãos oficiais de consulta e assessoria do Serviço de Saúde Pública, em Washington, DC.

No Brasil, segundo Oberdan R. Perrone, apesar do exemplo norte-americano ter demonstrado resultados positivos e excelentes, 0 processo de avaliação do trabalho médico, ou auditoria médica, "permanece quase ignorado".

A aplicação de processo idêntico, no campo ou área de atividades da enfermagem hospitalar, foi questão apenas de integração. A Liga Nacional de Enfermagem e a Associação Americana de Enfermeiras, com todas suas ramificações especializadas, trabalham de comum acordo com as organizações médicas, responsabilizando-se pela avaliação no setor de enfermagem da assistência médica-hospitalar, resguardada sua autonomia profissional.

As Comissões Conjuntas de Credenciamento de Hospitais são constituídas por profissionais de várias disciplinas, incluindo enfermeiras, muito embora a maioria seja do campo da medicina, o que é obviamente necessário dadas suas funções e responsabilidades. 
Houve portanto um processo de assimilação de métodos e práticas do grupo médico pelos demais grupos.

Desde meados da década de 50 têm sido publicados vários artigos sobre avaliação do trabalho da equipe de enfermagem e especificamente sobre "auditoria de enfermagem", inclusive como tema de tese.

Da mesma forma que o objetivo central da auditoria médica é a elevação do padrão de assistência médica hospitalar, na enfermagem é a melhoria de qualidade da assistência de enfermagem que o hospital se propõe a of erecer à comunidade, ou que tem por obrigação social of erecer.

Nada mais ético e razoável, portanto, que procurar, através de um processo de eficiência e utilidade comprovadas, evidenciar falhas, erros e inadequações que porventura ocorram ou existam nos serviços de enfermagem, às vezes com implicações legais que repercutem desfavoravelmente em todo o hospital.

Não é necessário muito conhecimento especializado para iniciar um processo de Auditoria de Enfermagem; o que é preciso sim, é de muita coragem para enfrentar o problema, humildade para reconhecer as falhas, honestidade de propósitos para dar continuidade à tarefa e liderança para criar condições para implantação de um sistema de avaliação.

\section{BASES LOGICAS}

Uma das maiores dificuldades no caso da enfermagem é traluzir o trabalho em seus componentes. Quais os índices que poderiam indicar a eficiência da enfermagem hospitalar?

Para começar, nossos hospitais, de um modo geral, não contam com serviços de enfermagem organizados como um modelo de sistema.

Não há definição clara dos objetivos a serem alcançados pelo serviço como um todo e pelas suas seções especializadas. Não há programas de trabalho coerentes com os objetivos propostos.

Os objetivos deveriam ser estabelecidos de forma clara e precisa e passíveis de mensuração, isto é, que permitam a aplicação de um método de avaliação ou de pesquisa, para traduzir as ações de enfermagem em dados estatísticos.

Quase sempre os objetivos são vagos e imprecisos, dificultando ou mesmo impedindo uma avaliação dos resultados das ações exe- 
cutadas para sua obtenção, em termos de mudança da situação do paciente, ou em termos de padrões estabelecidos como metas a serem alcançadas.

Ainda há a considerar que toda a atividade da enfermagem hospitalar está sujeita ao processo de planejamento, condicionada cada reciclagem do processo a uma avaliação, para termos comparativos.

Todos os conceitos já emitidos sobre enfermagem implicitamente exigem ações inteligentes dos profissionais, dentro de um plano racional que conduza a um curso de ação, com suas fases sistematicamente interligadas. Para a assistência de enfermagem, considerada um sistema aberto, onde o paciente é o objeto das mudanças, temos que considerar como entrada ou input uma série de elementos: Pessoal, ambiente, equipamento, sistema de informações, ações desejáveis e necessárias. A saída, produto ou out put será o resultado da combinação desses elementos com a situação paciente. Tais resultados devem ser mensurados, confrontados com padrões estabelecidos ou com expectativas.

Outro fundamento para a Auditoria de Enfermagem, a nosso ver, mais de caráter ético inter-profissional, é a aplicação da justiça. Por que uma alta média de permanência deve sobrecarregar apenas o grupo médico nas considerações de ineficiência ou inadequação?

Não restam mais dúvidas às autoridades sanitárias quanto a ser assistência médica hospitalar da responsabilidade não de um profissional apenas — o médico - mas de uma equipe interdisciplinar.

Grande enfoque recebe atualmente na psicologia médica, a tríade paciente - enfermeira - médico.

Com má enfermagem dificilmente haverá bons resultados do trabalho médico. Ambos devem ser avaliados sem parcialidades.

Por último acrescentariamos uma questão vital, sob o ponto-de-vista da administração hospitalar, que nos leva a considerar a alta relevância da Auditoria para a enfermagem: é a estreita vinculação que existe entre a administração hospitalar e a enfermagem, tanto estrutural como funcional.

A enfermagem, cada vez mais, pela natureza de suas funções e condições de trabalho, carece de estruturação lógica e racional. De acordo com a situação devem ser sua posição e suas finalidades. Aspirações e realizações ou eficiência devem caminhar juntas. Por delegação, na descentralização administrativa, os serviços de enfermagem recebem várias atribuições que lhes compete planejar, implementar, coordenar e controlar, com vistas a oferecer a melhor 
atenção de enfermagem possível aos pacientes. Para maior racionalidade no controle, necessário se faz o uso de medidas ou critérios de avaliação.

Por outro lado, pela centralização, cabe à administração a cobrança dos resultados obtidos, que devem ser fornecidos através de relatórios de qualidade, com dados estatísticos, e dentro de um esquema que permita comparação progressiva. A administração deve estar segura de como o Serviço de Enfermagem desempenha suas funções.

\section{PROPOSITOS}

Tentamos justificar o mais plenamente possível a necessidade de ntrodução do método ou processo de auditoria em enfermagem nos hospitais, porque consideramos deva ser uma atividade formal do Serviço de Enfermagem.

Como todo o método, deve ter um guia com objetivos bem claros.

Segundo Deeken (3), o guia deve servir como um meio para o Serviço de Enfermagem melhorar a qualidade do cuidado ao paciente. Paralelamente fornecerá dados para melhoria dos programas do Serviço de Enfermagem.

$O$ guia deve também ser preparado de tal forma que permita a identificação das áreas ou pontos fracos do serviço, para sua correção devida, deficiências que poderiam não ser percebidas de outro modo.

\section{OBJETO DA AUDITORIA}

Todas as informações para avaliação do trabalho médico são fornecidas pelo prontuário do paciente ou prontuário médico, como é mais conhecido na Administração Hospitalar.

Como instrumento legal o prontuário deve exibir também as informações, observações ou relatórios da enfermagem, informações essas pertinentes ao estado do paciente, cuidados prestados e evolução.

Teoricamente todas as enfermeiras concordam com o valor do prontuário e a necessidade das anotações da enfermagem. O que encontramos na prática é a utilização inadequada à situação.

Certa vez uma aluna em estágio de "Administração aplicada à Enfermagem", após uma aula sobre o valor das anotações de 
enfermagem, fez um levantamento de prontuários e chegou à seguinte conclusão quanto ao volume de anotações por categoria: atendentes $71 \%$, auxiliar de enfermagem 28,5\%, enfermeira $0,5 \%$. Quanto a qualidade, a maioria das anotações eram vistos ou cheques sobre os horários, outros não eram significativos: "comeu bem", "dormiu bem", "queixa-se de dor de cabeça", "tomou banho".

Tais anotações não revelam qualidade, pois não têm seqüência, não quantificam nada, não objetivam a situação do paciente, enfim não revelam planejamento dos cuidados para atender às necessidades de cada paciente em particular.

Com freqüência que chega a ser desalentadora, as anotações de enfermagem são praticamente inúteis, na maioria dos hospitais que já tivemos oportunidade de visitar em todo o País.

Expomos nossa opinião com a maior honestidade de propósito, o de ajudar na conscientização do problema. Não podemos pensar que deixando de trazer para discussão estas questões nos protegemos da crítica. Pelo contrário, estaremos voltando as costas para um problema básico e candente da enfermagem - a qualidade dos cuidados; estaremos ignorando que nosso público, pacientes, médicos e comunidade, têm algo a nos dizer. A própria atitude do médico, perguntando ao paciente se ele tomou tal e qual medicamento, é uma crítica aberta; se ele não recorre à anotação da enfermagem é porque nela não confia.

Todavia, mais doloroso que isso, pelo aspecto humano, é encontrármos um paciente com sede, sem coragem de pedir água para beber, pois temia a reação do pessoal de enfermagem. Que outras necessidades de enfermagem teria tido, que não foram sequer percebidas? Que dizer do caso de um paciente com aparelho de gesso na perna da qual, ao ser retirado o gesso, foi encontrada miíase extensa? O prontuário era lacônico, sempre "sem queixas". E de uma criança que apresentou hipertermia e recebeu um comprimido e uma ampola de Novalgina dados por dois elementos de enfermagem, sem nenhuma coordenação anterior e sem nenhum controle posterior, que foi encontrado por um médico-assistente, transpirando abundantemente, com hipotensão, quase inconsciente?

Revelariam os prontuários tais falhas? A casuística é grande, dada a oportunidade que já tivemos nos 18 anos de vida profissional; as medidas tomadas nada têm de positivo.

O uso do prontuário do paciente como fonte de dados, para um programa de auditoria de enfermảgem, não só é recomendável, para responder cientificamente a algumas questões de enfermagem, como é uma obrigação moral das chefias de enfermagem. 
Encontramos por vezes movimentos isolados, enfermeiras que se interessam em verificar diariamente os prontuários. Isto, porém, não conduz a uma avaliação sistemática dos serviços de enfermagem, não mede a qualidade da enfermagem do hospital, apenas dá àquela profissional, isoladamente, maior segurança e, naturalmente, pelo controle que mantém na sua unidade, gozará de maior prestígio e será devidamente valorizada.

A citação de casos deploráveis, acontecidos aqui e acolá, não confirma nenhuma hipótese e nem temos tal pretensão, já que não realizamos nenhuma pesquisa a respeito. Mas temos uma indagação: quem poderá afirmar que tais casos não acontecem diariamente numa mesma instituição?

Se os relatórios de enfermagem, que compõem a fotografia que se pode analisar e explorar, para verificação da qualidade do cuidado prestado, são imprecisos, incompletos, sem conteúdo significativo e por vezes com informações falseadas, que proteção estão os hospitais oferecendo à sua população de pacientes? Que provas existem, de que a enfermagem executa as ações que lhe competem para a promoção e manutenção e recuperação da saúde e reabilitação do paciente?

Quando poderemos analisar os componentes da enfermagem se não há registro devido de suas atividades? Dificilmente teremos resposta cientifica a estas questões, se não houver mudanças estruturais profundas na enfermagem, se não for introduzida nova tecnologia no trabalho, se não for iniciado um trabalho sistemático de levantamento da situação para posterior normalização das atividades e aplicação de medidas corretivas quando necessário.

\section{PRINCIPIO BASICO DE QUALIDADE}

O desprestígio que existe, entre os próprios elementos de cúpula da enfermagem, a respeito do planejamento de cuidado do paciente, deve ser analisado. Quais serão os motivos reais que levam à negação de um princípio básico para obtenção de qualidade na prestação de serviços de enfermagem? Que razões existem para a desintegração que se verifica entre o ensino e a prática da enfermagem? Quais os obstáculos que se opõem à existência de uma linguagem comum na enfermagem?

Não vamos fazer uma análise desses problemas agora, por duas razões muito simples: primeiro porque não é objetivo do nosso tema, o qual implica em avaliação de qualidade. Consideremos que qualidade deve resultar de um processo planejado com certo grau de racionalidade, isto é, de um processo cujos resultados na execução 
sejam cada vez melhores, à medida que se tem maior conhecimento da situação. Tal conhecimento permitirá identificação mais precisa dos problemas ou necessidades, priorização dos problemas a serem atendidos e medidas mais adequadas. O processo é contínuo e ascendente, não sendo possível sem planejamento. Em segundo lugar, porque a profundidade e extensão do problema reclamam uma pesquisa urgente.

Já dissemos em outras ocasiões e voltamos a repetir: Há uma nova tendência, na educação moderna, de integrar teoria e prática. A enfermagem terá que desenvolver seus meios de integração se é que pretende manter o status alcançado. O cuidado de enfermagem aos pacientes não é campo de lutas que termine com vencidos e vencedores. Docentes e praticantes da profissão devem procurar soluções adequadas aos problemas de assistência que lhes cabe prestar e o paciente deve ser a motivação para trabalho em conjunto.

Desejos de glória não se coadunam muito bem com o papel que a enfermagem deve assumir na sociedade de hoje. Por outro lado, a indiferença e o descaso pelo desenvolvimento profissional podem impedir o diálogo e o entendimento.

Certa vez uma colega tentava nos provar que o trabalho em equipe exige mais pessoal e mais tempo da enfermeira para o planejamento de cuidado, tempo esse que ela, enfermeira, não tem. Na mesma época uma aluna de $3 .^{\circ}$ ano, empolgada com a aula sobre organização do trabalho em equipe, se propôs a experimentá-lo na clínica onde estagiava. Os resultados favoráveis a esse tipo de trabalho superaram sua própria expectativa.

Haverá por acaso na enfermagem uma separação entre a geração antiga e a nova, causada pelos novos métodos de trabalho? Como serão recebidas as futuras enfermeiras, hoje alunas, que se revelam cada vez com maior espírito de criatividade e inovação, se há atualmente defasagem de conhecimentos entre os que ensinam e os que praticam enfermagem?

Se o paciente, que é "teoricamente" o centro das nossas atividades, só recebe as sobras do tempo das enfermeiras, que será da enfermagem profissional? Desaparecerá? O que virá em seu lugar?

Ontem a enfermeira se via assoberbada por tarefas administrativas, hoje ela se vê assoberbada pelos conhecimentos científicos que deve dominar e aplicar no cuidado do paciente.

Há uma nova perspectiva na enfermagem, novas responsabilidades e exigências para poder atuar eficientemente na equipe de saúde. 
Tudo indica que os métodos de trabalho e técnicas do passado não podem mais responder às necessidades do momento atual da enfermagem. Forçosamente terão que ser substituídos, renovados, ou pelo menos reajustados.

A nosso ver a Auditoria de Enfermagem não pode permanecer como processo ignorado; através dela novos caminhos poderão ser apontados. A qualidade do cuidado de enfermagem não se mede pelo tempo gasto em telefonemas, escalas, requisições, controle de equipamento, manutenção da ordem e limpeza, contagem de rol de roupa e outras atividades burocráticas. A qualidade é avaliada pelo tipo de cuidado que é prestado ao paciente, análise das suas necessidades, ensino e orientação que recebe, prevenção de defeitos e sequelas, recuperação rápida, alto grau de satisfação do paciente, família e médicos quanto ao cuidado prestado, conteúdo significativo das informações sobre o estado e evolução do paciente, observação dos padrões estabelecidos para o cuidado de enfermagem, resultados alcançados na aplicação de novos métodos e técnicas específicas de enfermagem, pesquisas realizadas nas áreas especializadas da enfermagem, orientação e treinamento adequado do pessoal, relatórios quantificados da qualidade do serviço de enfermagem, elaboração dos instrumentos de administração exclusivos da enfermagem, motivação e moral do pessoal, permanência do pessoal em serviço, baixo absenteismo do pessoal, fichas funcionais do pessoal isentas de reprensões, custo racional dos serviços, distribuição adequada das tarefas ao pessoal, ausência de interferências estranhas nas decisões de enfermagem, conceito que a enfermagem goza na instituição, respeito e conhecimento que a comunidade revela a respeito de equipe de enfermagem, devida solução e apoio que a administração dá aos problemas da enfermagem, produção literária dos profissionais de enfermagem.

E realmente muito o que a sociedade moderna espera da enfermagem e, sem planejamento, jamais conseguiremos corresponder à expectativa. Se não há objetivos ou meta a alcançar, então realmente não há necessidade nem de planejar e muito menos de medir.

Os itens citados são aceitos universalmente, portanto é nossa obrigação tentar alcançá-los. De todos os citados pelo menos dez deles podem ser objetos de mensuração pelo prontuário do paciente; outros tantos podem ser medidos ou avaliados através de planos de trabalho e atuação do pessoal; e ainda alguns por levantamento de opiniões de pacientes, médicos, familiares e comuniduic. 


\section{PROGRAMAÇÃO DA AUDITORIA}

Tratando-se, como já foi dito, de uma atividade que deve estar integrada na administração do Serviço de Enfermagem, há necessidade de uma programação específica. E recomendável que inicialmente seja constituído um grupo de trabalho para estudar o assunto, estabelecer bases, diretrizes, objetivos, normas, constituição e método de trabalho da Comissão de Auditoria de Enfermagem, incluindo o sistema de avaliação.

O relatório do grupo de trabalho deverá ser submetido ao corpo de enfermeiras do serviço para discussão. Após sua revisão e aprovação é imprescindível o conhecimento, pela alta administração do hospital e Corpo Clínico, pois será um novo programa de trabalho cujo êxito dependerá do apoio dos dois grupos.

Como orientação para um ponto de partida, considerando a inexistência de experiência nacional, apresentamos os objetivos elaborados por um grupo de docentes e enfermeiras da Universidade de Kentucky, para a Comissão de Auditoria, cujo funcionamento nos foi dado a conhecer em 1970 .

\section{Objetivos da Comissão de Auditoria}

1 - Melhorar a qualidade do cuidado de enfermagem por meio de:

- revisão sistemática dos relatórios de enfermagem;

- orientação para registro de informações mais úteis e pertinentes;

- motivação do pessoal para melhorar habilidade em registrar observações sobre os pacientes;

- discussão para alertar o pessoal quanto aos aspectos médico-legais do prontuário do paciente;

- demonstração de necessidade de mudança ou revisão de guias e normas de enfermagem;

- fundamentação para os programas de desenvolvimento de pessoal, centralizados na melhoria da qualidade de comunicação.

2 - Projetar e revisar impressos e formulários para auditoria.

3 - Analisar e revisar, periodicamente, prontuários selecionados de pacientes de todas as unidades de internação.

4 - Discrtir, periodicamente, com as Assistentes do Serviço de Eittermagem resumu dos resultados encontrados. 


\section{Desta Comissão Participam:}

1 Diretor-Assistente do S.E. (rodizio cada 2 anos)

1 Diretor da Divisão de Escriturários (rodizio anual)

1 Diretor-Assistente de Educação em Serviço (permanente)

1 Auxiliar de Enfermagem (rodizio anual)

3 Líderes da Equipe de Enfermagem

2 Enfermeiros-Chefes (Senior Team Leader) - Vive-Presidente e Presidente da Comissão (2 anos com rodizio de posição) .

\section{Revisão de Prontuários}

Itens para revisão dos prontuários, preparados por Fisher para o Hospital Thayer, Waterville,

1 - Ordens médicas (diagnósticos, plano terapêutico, cirurgia, prescrições)

2 - Prontuário médico (data, matrícula, admissão, pós-operatório, parto etc.), omissões de registro:

3 - TPR, PA, internação, alta, remoção de suturas e drenos, transfusão, prescrições, outros) .

4 - Termo de responsabilidade e permissão para tratamento, necropsia, alta e pedido, uso de roupa particular etc.

5 - Controle (rol de roupa, admissão e alta, relatório de acidente, certificado de nascimento etc.).

Além do impresso elaborado para a revisão de prontuários, de acordo com os itens acima, há um guia para responder às seguintes perguntas:

1 - As ordens médicas foram devidamente seguidas?

2 - Se houve atrasos foram dadas as razões?

3 - Algum tratamento (ou medicação) foi continuado após ter sido suspenso pelo médico?

4 - Algum tratamento (ou medicação) foi feito sem ordem médica?

5 - O médico foi notificado quando a prescrição de narcótico ultrapassou o limite de tempo?

6 - As instruções médicas são claras e orientam a enfermagem?

7 - Existe plano escrito de cuidado de enfermagem? 
8 - O plano está de acordo com as necessidades do paciente?

9 - O plano é adequado para todos os plantões?

10 - O plano engloba: sugestões para o conforto físico do paciente, necessidades especiais, considerações sobre bem-estar mental e espiritual?

11 - As instruções para os cuidados são claras para todo o pessoal de enfermagem?

12 - O prontuário revela a execução de programa de ensino ao paciente?

13 - Quando necessário foram tomadas medidas de proteção contra acidentes?

14 - Há evidências, por escrito, de que o paciente foi orientado quanto ao hospital?

15 - Sugestões para melhoria dos cuidados de enfermagem.

16 - Comentários sobre aspectos do cuidado prestado, que foram considerados muito úteis ou excepcionalmente bons.

A partir dos dois formulários devidamente preenchidos para cada prontuário selecionado, a Comissão constituída poderá, com os dados e informações colhidos, elaborar outros instrumentos de controle, por exemplo, fichas para registro de observação sobre o pessoal, quadros, tabelas, fichas para sugestões, entrevistas etc. As fichas individuais devem ser arquivadas como material "confidencial".

\section{CONCLUSÕES}

Considerando o assunto da mais alta relevância para melhoria da qualidade do cuidado de enfermagem, e considerando que o planejamento dos cuidados de enfermagem dependem em certo grau, do plano terapêutico médico e, ainda, os resultados deste dependem em parte da enfermagem;

Recomendamos :

1 - que as diretoras de Serviço de Enfermagem procurem analisar o problema e implantar o processo, indicando para isso uma Comissão da qual devam participar docentes que se utilizam do hospital como campo de prática;

2 - que seja incluída nas Comissões de Auditoria a participação de representante do Corpo Clínico. 


\section{BIBLIOGRAFIA CONSULTADA}

1 - WEBSTER'S DICTIONARY - Webster's Third New International Dictionary (and Sevan Language dictionary). Britannic World Language Dictionary by Robert C. Preble. USA, 1966.

2 - PERRONE, Oberdam Revel - Análise e Avaliação do Trabalho Médico. Cadernos de Estatística Hospitalar, n. ${ }^{\circ}$ 1, Rio de Janeiro, 1966.

3 - DEEKEN, Mary H. Louise - A Guide for the Nursing Service Audit. The Catholic Hospital Association, S. Louis, 1960 .

4 - UNIVERSIDADE DE KENTUCKY - Manual do Serviço de Enfermagem do Centro Médico Albert B. Chandler, Hospital Universitário, 1970.

5 - FISHER, Pearl R. - The Nursing Audit. Nurs. Outlook 5 (10) : 590-592, 1957.

6 - RIBEIRO, Circe de Melo - Novas Tendências no Ensino e Prática da Enfermagem. Revista da EEUSP, 4 (1-2) : 21-39, mar. set., 1970 .

\section{OUTRAS INDICAÇÕES BIBLIOGRÁFICAS}

1 - DEMING E.A. - A Practicing System of Professional Nursing Nurs. Clin. North Am. 6 (2): 311-320, jun., 1971.

2 - FRANCO, Hilario - Auditoria. Rev. Paul. Contab. 44 (418) : 5-6, 1967.

3 - HOWLAND, Daniel e Mc DOWELL, Wanda E. - The Measurement of Patient Care: a Conceptual Framework. Nurs. Rev. 13 (1) : 4-7, Wint, 1964.

4 - MARRA, Ernesto - Normas de Auditoria. Rev. Paul. Contab. 44 (418): 7-17, 1967.

5 - McGUIRE, R.L. - Bedside Nursing Audit: Am. J. Nurs 68 (10) : 2.146-2.148, oct., 1968.

6 - MYERS, R.I. e SLEE, V.N. - Medical Statistics Tell the Story at a Glance. Mod. Hosp. 93 (3): 72-75, Sep. 1959. 